NASA Technical Memorandum 102297

\title{
Photovoltaic Module On-Orbit Assembly for Space Station Freedom
}

T. Sours

Lewis Research Center

Cleveland, Ohio

R. Lovely and D. Clark

Rockwell International

Rocketdyne Division

Canoga Park, California

Prepared for the

24th Intersociety Energy Conversion Engineering Conference cosponsored by the IEEE, AIAA, ANS, ASME, SAE, ACS, and AIChE Washington, D.C., August 6-11, 1989

\section{N/SA}




\title{
PHOTOVOLTAIC MODULE ON-ORBIT ASSEMBLY FOR SPACE STATION FREEDOM
}

\author{
T. Sours \\ NASA Lewis Research Center \\ Cleveland, $\mathrm{OH} 44135$ \\ and \\ R. Lovely and D. Clark \\ Rocketdyne Division, Rockwell International \\ Canoga Park, CA
}

\begin{abstract}
One of the elements of the Space Station Freedom power system is the Photovoltaic (PV) module. These modules will be assembled on-orbit during the assembly phase of the program. These modules will be assembled either from the shuttle orbiter or from the Mobile Servicing Center (MSC). This paper describes the different types of assembly operations that will be used to assemble PV Modules.
\end{abstract}

\section{Introduction}

Freedom will be constructed on-orbit beginning in the mid 1990's. The construction of Freedom will require about twenty National Space Transportation System (NSTS) missions over a period of three years. The on-orbit configuration and assembly sequence are in the process of being optimized to satisfy program and NSTS recquirements that must be satisfied. In order to ensure that the station can be successfully assembled on-orbit. the assembly operations requirements must be considered early in the design phase of the flight hardware. The current baseline configuration with four PV Modules is shown in Figure 1.

\subsection{Assembly Requirements}

During the baseline phase. Freedom will be powered by photovoltaic modules. More power generation capability will be added with either photoroltaic modules or with solar dynamic modules during the growth phase.

Each assembly mission in the assembly sequence will leave on-orbit a fully functional and survivable spacecraft. The effect of failed equipment on-orbit and the subsequent required maintenance and logistics during the assembly phase must also be considered. The assembly sequence must also support contingency and abort operations of the NSTS. The launch manifest for each mission must meet all of the orbiter constraints on volume, mass, center-of-mass, physical clearances, safety. structural integrity and other NSTS requirements. The on-orbit operations must not exceed the arailable EVA. IVA. power. pointing capability and other resources available during the assembly phase.

One of the objectives of the assembly sequence is to prevent the need for "throw away" hardware that will only be used to temporarily support Freedom during its 
assembly phase. The goal is to build Freedom in such a way that each piece of equipment is installed in its operating location without the need to remove or relocate it at a later point in the assembly sequence.

\subsection{On-Orbit Assembly Operations}

Since the Space Station Freedom Program is still in a definition phase, the concepts for the various systems are in a state of flux. This work is part of ongoing activities in the area of on-orbit assembly planning. As the design process progresses this work will be refined to ensure the successful integration between systems on the station. Extensive computer simulation will be used during this process. This will be complemented by neutral buoyancy testing of selected hardware. Shuttle flight demonstrations will be used prior to the start of the space station assembly process to verify the performance of the telerobotic systems.

\section{Electric Power System}

The NASA Lewis Research Center has the responsibility to produce the electric power system (EPS) for Space Station Freedom. The Rocketdyne division of Rockwell International Corporation in Canoga Park, California is the prime contractor for this effort. This includes the design, clevelopment. manufacturing, assembly planning and maintenance planning for the end-to-end system architecture.

The two main parts of the power system are the Solar Power Modules for power generation and energy storage and the Power Management and Distribution System which will manage and deliver power to the user systems. |3|
The space station will be powered by 1 wo solar power modules. These solar power modules will be built up from a combination of solar photovoltaic (PV) modules and solar dynamic (SD) modules. The port and starboard solar power modules on the station will be interchangeable.

The solar power modules are located on either end of the transverse boom. They are separated from the rest of the station by alpha gimbals. The purpose of this gimbal is to provide sun tracking of the solar powel modules. The alpha gimbals must make one complete revolution for each orbit of the Earth. The station will be in a circular orbit. 220 nautical miles above the Earth surface with a 28.5 degree inclination to the equator. In this orbit a satellite will take ninety minutes to circle the globe.

\subsection{PV Module Description}

The PV module consists of three large components that will to be installed onto the space station truss. These are the Integrated Equipment Assembly (IEA) and two Beta Gimbal/Solar Array (BG/SA) assemblies.

The Integrated Equipment Assembly (IEA) will be pre-integrated on the ground during ground processing. It will contain the battery and PMAD Orbital Replacement Units (ORU) for one PV module. On-orbit the IEA will be attached to the truss, the electrical connections mated and the deployable pumped loop radiator will be deployed. The thermal cooling loop will not require any fluid connections to be made on-orbit.

The beta gimbal and the solar array will also be preintegrated on the ground. On-orbit they will be installed in the truss and their 
respective electrical connections mated. No active cooling of these devices is required.

The inboard PV module will include two bays of space station truss, cable trays, EVA System hardware as well as the components mentioned above. The outboard PV Modules will be the same as the inboard modules with the addition of two truss bays to provide clearance from the inboard modules.

The PV module launch package consists of the Integrated Equipment Assembly, two Beta Gimbal / Solar Array Assemblies, Truss and Utilities. The launch cradle to support these items during the launch phase of the NSTS mission is built into the structure of the IEA.

\section{On-orbit Assembly Operations}

Careful planning is being done to ensure that the station can be assembled on-orbit. Crew time, equipment, data, power and other resources all must be utilized to perform the on-orbit assembly. One goal of assembly planning is to minimize the EVA time that is required to assemble the station. This will be accomplished by designing the flight hardware such that it is easily assembled on-orbit and through the use of telerobotic devices to aid the astronauts in their tasks.

As Freedom grows the assembly operations will be supported increasingly by station based resources. The Mobile Transporter (MT) will be powered by the NSTS on the first missions and from the station EPS. on later flights. The EVA and IVA astronauts will be supplied by either system. As the station grows it will become less dependent on a visiting orbiter for assembly resources. When Freedom reaches its' Permanently
Manned Capability (PMC) assembly activities can be conducted without the presence of an orbiter.

EVA astronauts will perform the majority of the assembly tasks on the station. The IVA crew will be able to manipulate the Astronaut Positioning Systems (APS's) to position the EVA astronauts for assemble operations. [5]

Translation of crew and equipment is one of the most time consuming tasks of station assembly. Though the use of remotel! operated manipulators and astronaut positioning aids a portion of the assembly work load will be shifted from the EVA crew to the IVA crew. The function of equipment retrieval and crew positioning will be performed by IVA astronauts operating the robotic systems on the station and shuttle. The EVA astronauts will be able to more effectively use their time to perform those tasks that require the dexterous capability.

The Flight Telerobotic Servicer (FTS) will be available to support Mobile Servicing Center (MSC) based assembly of the PV modules. |6| It may be mounted onto the Space Station Remote Manipulator System (SSRMS) to assist in PV module assembly. The SSRMS will be used to release the PV module components from the launch cradle. It will also serve as an alignment and stabilization aicl for the EVA astronauts as they install the transition structures between the PV components and the space station truss.

For those EPS elements requiring automated deployment (solar array blankets) the deployment sequence will be controlled by 
IVA crew. A backup deployment method via EVA must be available for each automated deployment sequence.

\section{NSTS Based Assembly Operations}

The current assembly sequence [1] manifests a PV Module on the first assembly mission. This first element launch (FEL) will be constructed out of the cargo bay of an orbiter vehicle. The orbiter will serve as a base of operations for this activity. The MT will include the APS. This device will transport and position EVA astronauts so that they can effectively assemble and later maintain Freedom.

On the FEL the equipment that will provide the needed assembly capability must be included as well as all of the systems that constitute a function on the station. The Assembly Work Platform (AWP) will be the first item to be assembled on-orbit. This device provides a stand-off from the cargo bay and a stable frame to assemble the truss in. The MT is mounted on the outward end of the AWP. This derice will securely hold the nodes of the truss as it is assembled and the proper equipment installed. The MT will be used to translate bays of the truss away from the orbiter as they are completed.

During the assembly of the first two PV modules there will be a limit of two six hour long EVA periods that can be utilized to perform the necessary EVA assembly operations.

\subsection{NSTS Based Assembly Scenario}

The assembly of the PV Module will begin after the AWP and MT have been erected in the orbiter cargo bay and checked out. The first bay of truss will then be erected. [2]
This haly will contain the Beta Gimbals and their respective transition structures. The AWP, MT and this first assembled ba! of truss is illustrated in Figure 2.

The SRMS will retrieve the first beta gimbal/solar array from the cargo bay and position it into the face of the truss so that the EVA astronauts can attach it to the beta transition structures. The MT will rotate the assembly 180 degrees to allow for the installation of the second heta gimbal/ solar array. This is shown in Figure 3.

The MT will rotate 90 degrees and the LVA crew will install the utility trays onto the beta gimbals and begin assembly of the second bay of truss. The SRMS will retrieve and position the IEA into the center of this rruss bay as it is built. Figure 4 shows an EVA astronaut installing the transition structure that secures the IEA in place.

The next step is for the EVA crew to untalch and deploy the radiator. The PV Module at the conclusion of the EVA activities is shown in Figure 5.

The first PV Module will be one item on the launch manifest for this assembly mission. After its' assembly the crew will assemble the remaining equipment to produce the configuration illustrated in Figure 6.

\section{MSC Based Assembly Operations}

The MSC will be used as the base of operations for assembly activities that must be conducted away from the docked orbiter. The MSC will be transported on the truss by the MT. The MSC will provide for the temporary stowage of equipment on its base structure as well as a manipulator arm similar to those on the orbiter fleet. The 
SSRMS will provide equipment retrieval and positioning capability to support on-orbit operations. [4]

The second PV module delivered to orbit will be assembled using the MSC. In this second PV module assembly mission the launch packaged PV module must be removed from the cargo bay and attached to the MSC for transportation to the assembly operations site.

IVA astronauts will be used during assembly operations to control the various telerobotic equipment that will support the assembly activities being conducted external to the pressurized environment of the station.

The Shuttle Remote Manipulator System (SRMS) will be used to remove equipment from the cargo bay of the orbiter. The equipment will then be handed off to the SSRMS and stowed on the MSC.

The SSRMS is the station version of the shuttle arm. $|4|$ It will be used to retrieve and position EVA crew and equipment. The SSRMS will be capable of being operated from within the pressurized living environment of the station, from an orbiter. or from an EVA control station.

No EVA crew will be needed to remove items from the cargo bay and stow them onto the MSC. The Truss strut/node packages and the transition structure packages will be temporarily stowed onto the MSC for transportation to the assembly operations site.

\subsection{MSC Based Assembly Scenario}

After the orbiter has docked to the station the PV modules will be transferred to the Mobile Servicing Center. To do this the orbiter SRMS will grasp a grapple fixture located on the PV module cradle. The SRMS will then remove the PV module launch package from the cargo bay and position it so that the station's SSRMS can grasp a second grapple fixture. After this is accomplished the SRMS will release its grapple fixture so that the SSRMS will be free to position the PV Launch Package onto the MSC base unit. The PV launch package is secured onto the MSC by a third grapple fixture on the launch cradle with a corresponding capture mechanism located on the body of the MSC.

The truss structure package, the transition structure package and the utility tray package will similarly be removed from the cargo bay and stowed onto the MSC.

This process of removing the PV module from the cargo bay and stowing it onto the MSC will be controlled by the IVA crew without the aid of FVA astronauts.

When all of the items required to build one PV module have been removed from the orbiter and stowed for transport. the Mobile Transporter will then begin its slow journey to the work location.

The station IVA crew will command the alpha gimbal to stop and align itself so that the MT can make the alpha gimbal crossing.

The MT will travel to the work site and stop. Assembly of the outhoard PV module begins with the arrival of the EVA crew $|7|$. The EVA crew will be transported from the airlock to the assembly operations site by the Crew and Equipment Translation Aid (CETA). 
The EVA crew will ingress the APS foot restraints and prepare the utility deployment device.

The MT will then index forward one truss bay. As it indexes the utility deployer will deploy five meters of utility tray. The EVA astronauts will secure the deployed utility trays to the truss structure. The APS will position the EVA astronauts so that they can make the needed connections. The remaining bays will be constructed in a similar fashion. The last bay of truss will not have diagonals on the upper and lower faces in order to allow the beta gimbals to be placed in the center of those truss faces. Figure 7 illustrates truss assembly.

After the truss structure has been assembled. the PV module components will be installed. The SSRMS will grapple the upper beta gimbal/solar array package and reposition it into the center of the truss face to be installed. The EVA crew will attach the transition struts to the corners of the truss face. The lower beta gimbal/solar array will be installed in a similar fashion. After the beta gimbal/solar arrays are securely fastened to the truss structure. The EVA crew will retrieve the transition utility tray and install them onto the beta gimbals. This is illustrated in Figure 8.

A diagonal truss strut will be removed from the adjacent truss bay to allow for IEA installation. The SSRMS will grapple the IEA and reposition it into the center of the truss bay. The SSRMS will be used to align and stabilize the large IEA so that the EVA crew can install the transition structure that secures it to the truss. The installed IEA is illustrated in Figure 9. The EVA astronauts will complete their tasks by deploying the pumped loop radiator and installing the transition utility tray. The assembled PV Module is illustrated in Figure 10.

\section{References}

1.20/13 Assembly Sequence: Space Station Freedom Program

2. Watson, Judith I. ; et. al.: Mobile Transporter Test Results - An Assembly. Concept for Space Station and Large Space Structures, NASA TM 100661 , August 1988.

3.Rockwell International. Rocketdyne Division : Power System Description Document, RI/RD 88-633. 28 October 1988 4.SPAR Aerospace. Presentation to representatives of the NASA Lewis Research Center, Meeting in Toronto.Canada, July, 1988.

5. McDonnel Douglas Aeronautics and Astronautics Corporation. Presentation to the EVA System Working Group. Meeting at Houston.Tx, July, 1988.

6.NASA Goddard Space Flight Center. Presentation at the FTS Implementation Meeting, Meeting at Cleveland, $\mathrm{OH}$, November, 1988.

7. Sours, Thomas J. ; A Definition Study of the On-orbit Assembly: Operations for the Outboard Photoroltaic Power Modules for space Station Freedom. NASA TM 102006. March 1989. 


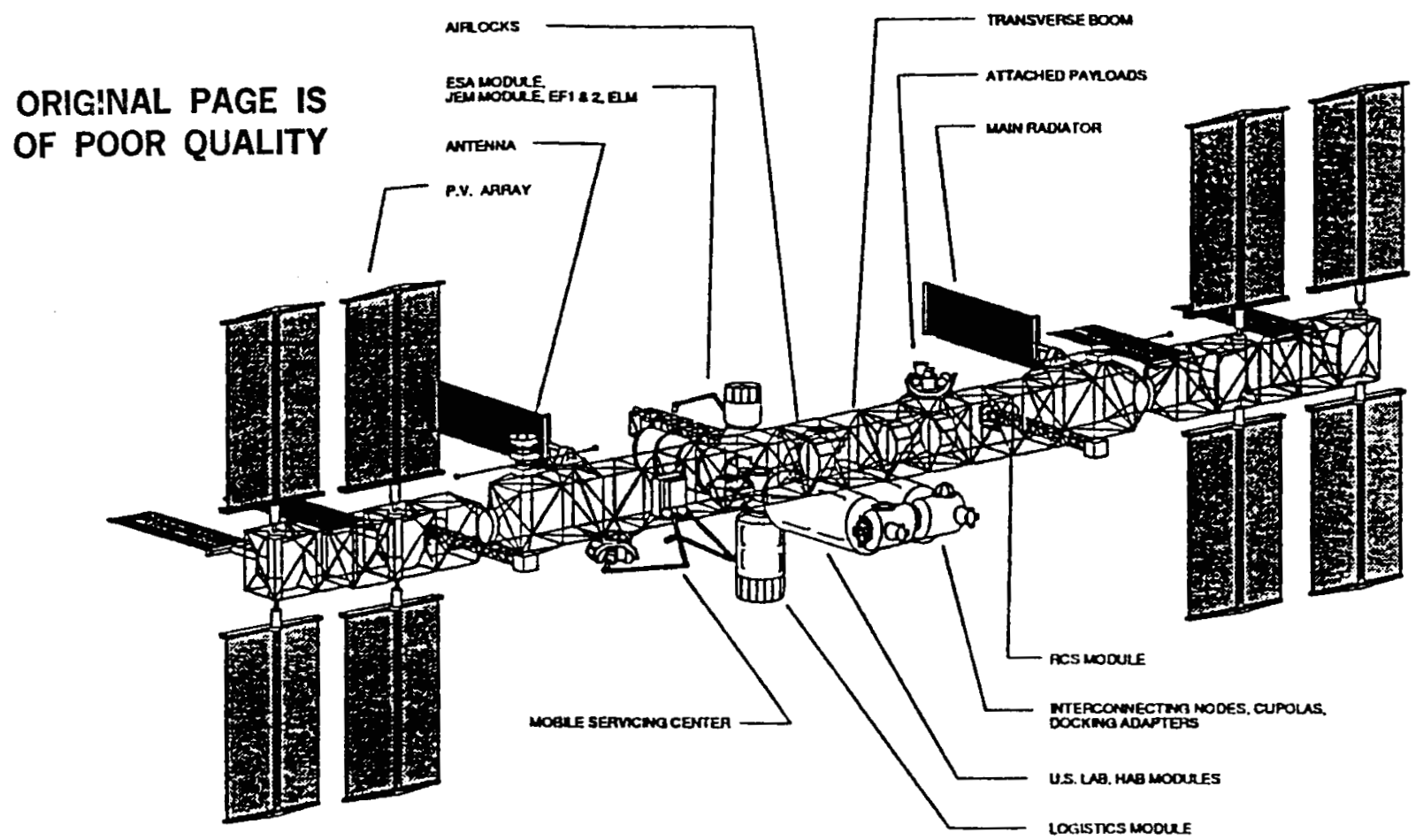

Figure 1 Space Station Freedom Configuration

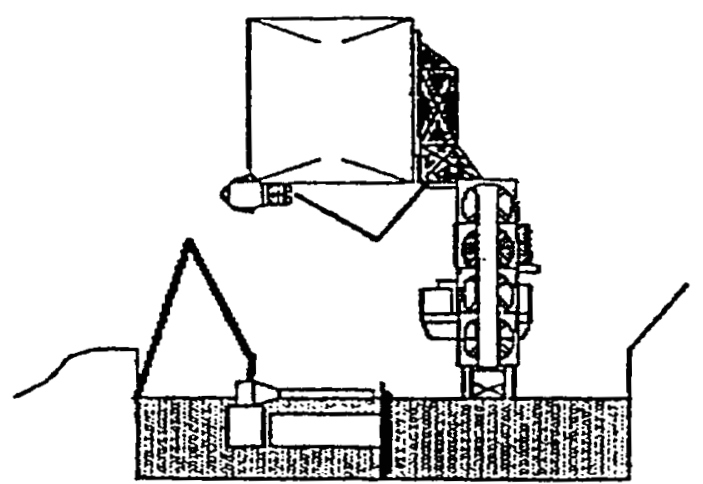

Figure 2 Assemble First Truss Bay

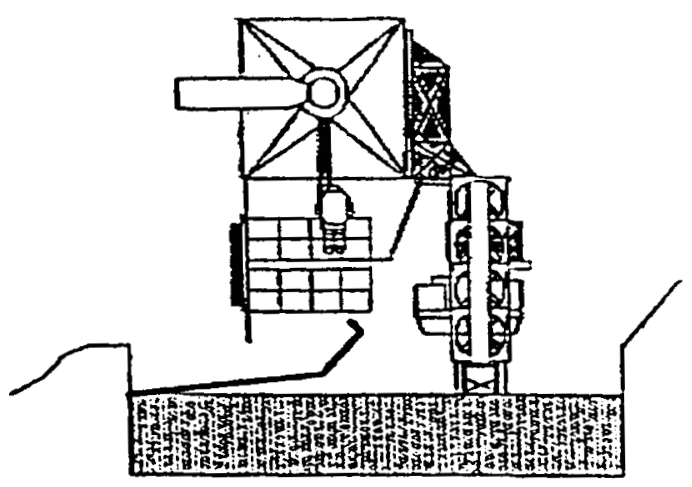

Figure 4 Install IEA

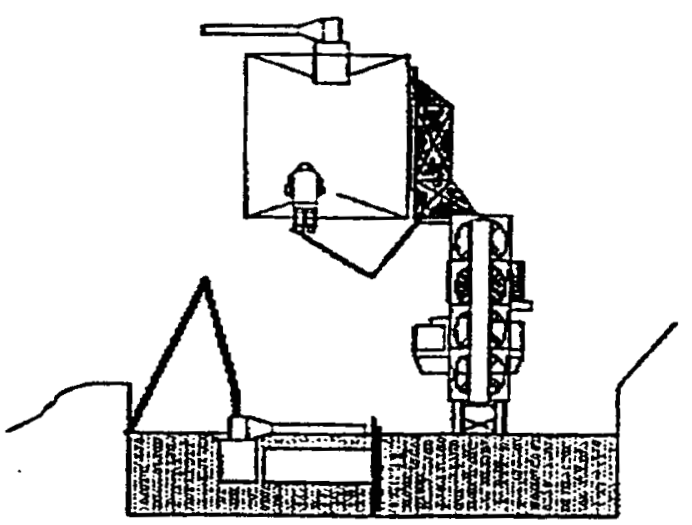

Figure 3 Install Beta Gimbal / Solar Array

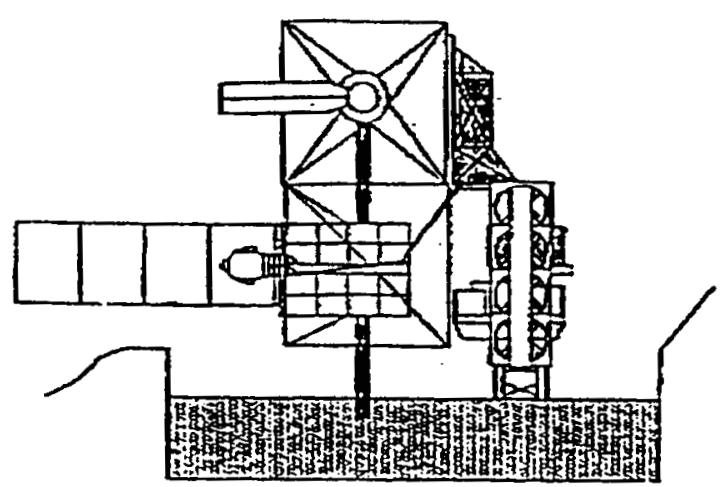

Figure 5 Assembled PV Module 


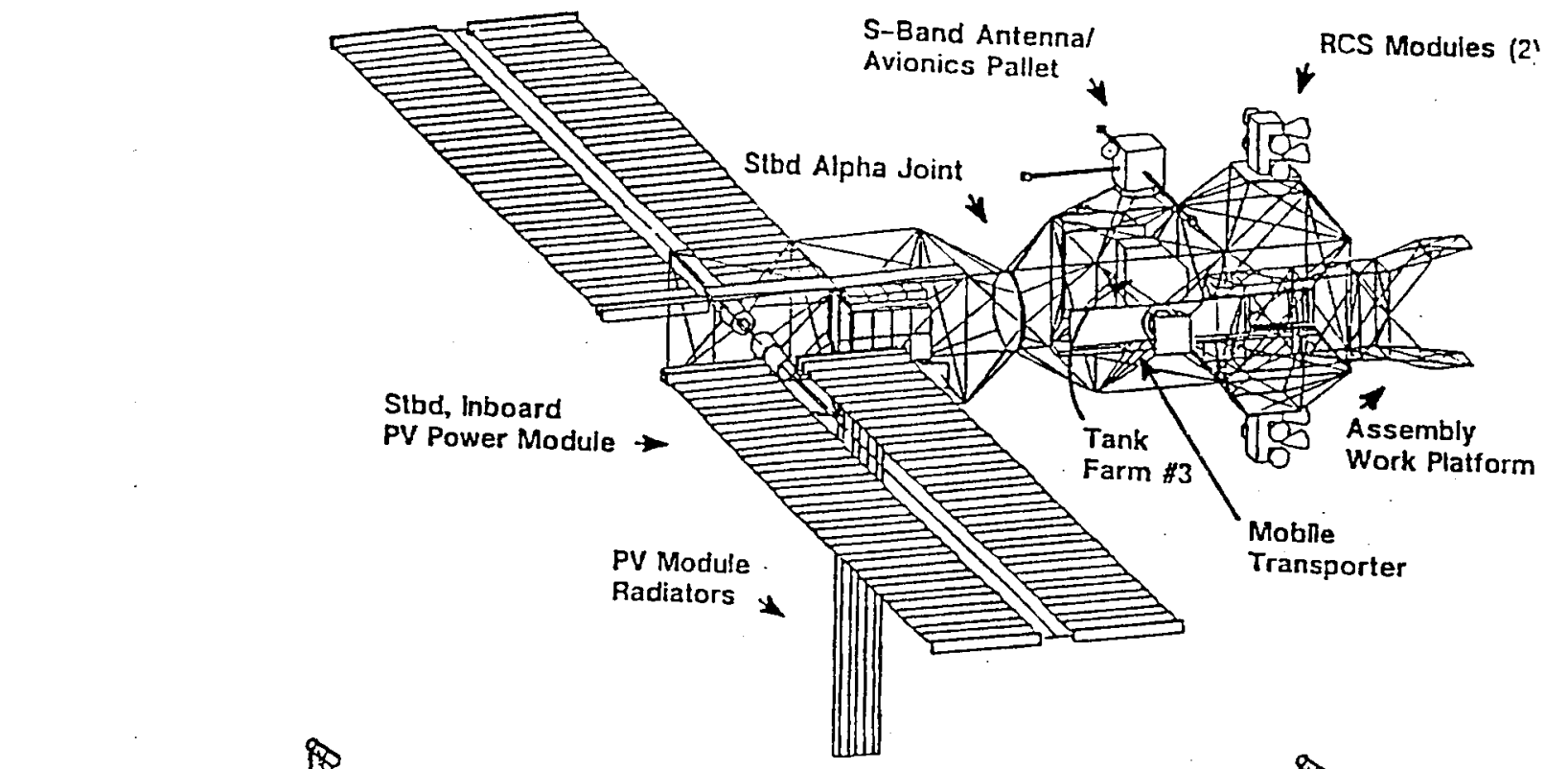

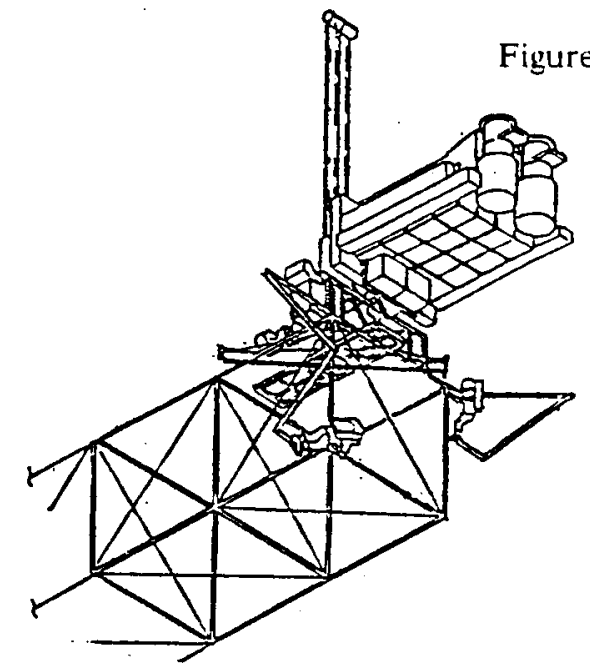

Figure 7 Assemble Truss Bays

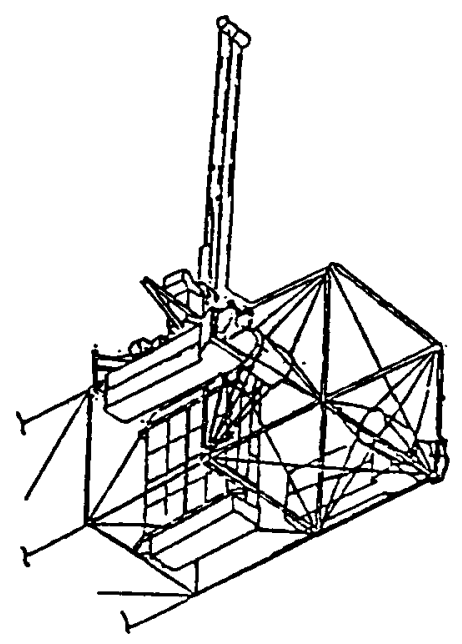

Figure 9 Install IEA

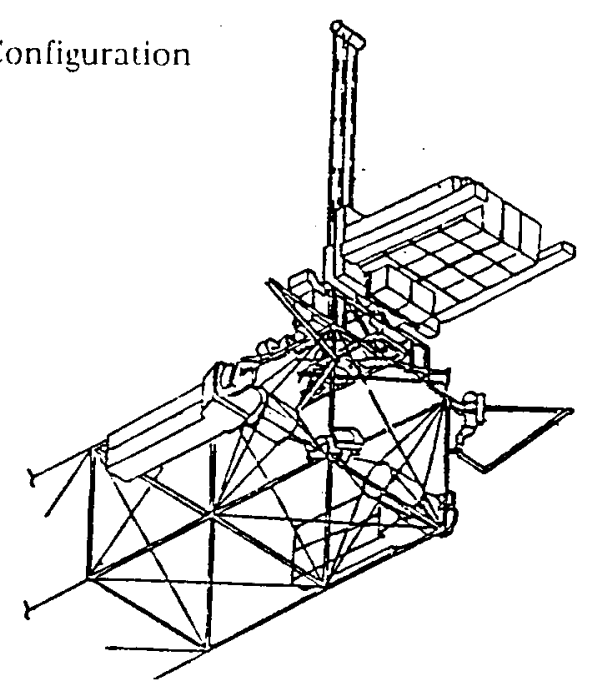

Figure 8 Install Beta Gimbal/Solar Arrays

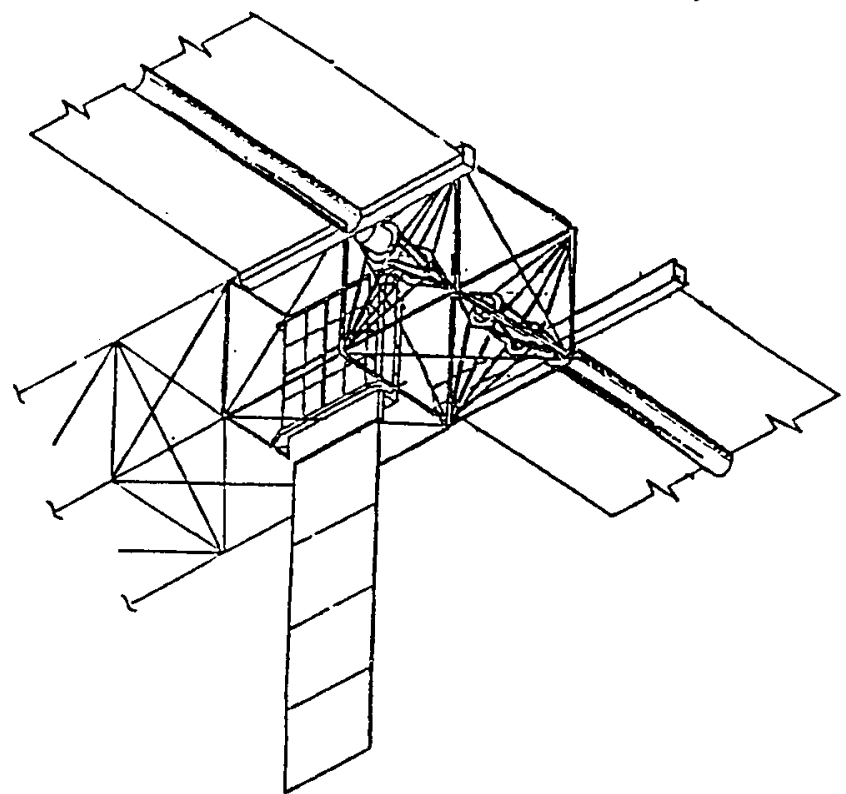

Figure (1) Assembled PV Module 


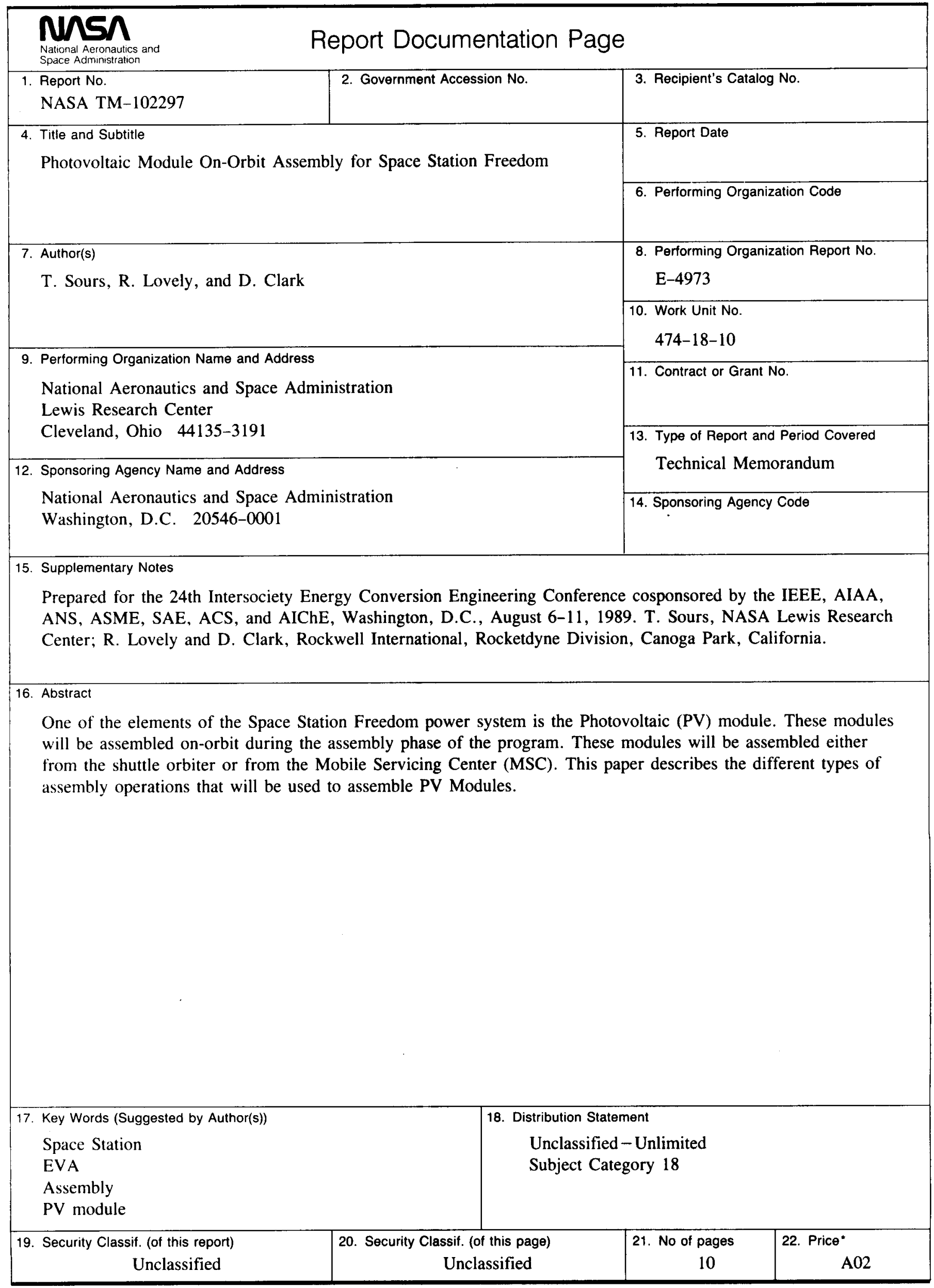

